\title{
DIMENSÃO ESTÉTICA EM TORNO DA \\ PRODUÇÃO LÍRICA DE GAMA MALCHER
}

\author{
AESTHETIC DIMENSIONS AROUND \\ THE GAMA MALCHER OPERATIC WORKS
}

\section{Márcio Leonel Farias Reis Páscoa \\ UEA}

\section{Resumo}

Este artigo faz uma síntese interpretativa da obra lírica de José Cândido da Gama Malcher (18531921), nomeadamente as suas óperas Bug Jargal (1890) e Jara (1895), estreadas no Teatro da Paz. Para isso, foi traçado um resumo da atividade teatral musical da Amazônia que antecedeu a participação de Malcher, assim como se evidenciam aspectos estruturais da organização das temporadas líricas do Teatro da Paz durante o período de 1880 a 1907, referentes ao Período da Borracha. Também são identificadas as fontes de Malcher que o inspiraram em ambas as óperas, de modo a conectá-lo com o contexto mais alargado das correntes estéticas e estilísticas da arte ocidental no século XIX.

\section{Palavras-chave:}

Gama Malcher; Ópera; Amazônia;

Belém; Teatro da Paz.

O descobrimento de meios tecnológicos, que favorecessem o uso da borracha silvestre, impulsionaram a economia do norte brasileiro, a partir de meados do século XIX, até seu declínio em finais da primeira década do século $X X$. Os recursos financeiros recebidos, anualmente, pelas províncias do norte se multiplicaram de maneira impressionante. Desta forma, criaramse as condições para fazer reformas urbanas significativas. Foi intentada uma política de colonização de terras nas províncias do Pará e Amazonas, causando grande imigração interna e externa, especialmente do nordeste do Brasil, e de pessoas oriundas da Europa. Os programas educativos que se empregaram para que a instrução pública alcançasse altos níveis de inclusão social lograram êxito, especialmente

\section{Abstract}

This article brings an interpretative synthesis of José Cândido Gama Malcher's (1853-1921) operatic works, 'Bug Jargal' (1890) and 'Jara' (1895), premiered in Teatro da Paz. For this purpose it was tracked the operatic background in Amazon before Malcher, as the evidences of structural aspects of Teatro da Paz lyric seasons in the Rubber Boom (1880-1907). The Malcher sources for both operas are also identified, in a such way for connect him to the most large context of XIXth century aesthetic and stylistic Western Art.

Keywords:

Gama Malcher; Opera; Amazon;

Belém; Teatro da Paz.

na recentemente criada província do Amazonas, outrora uma capitania cujas terras estavam dentro do Grão Pará1.

A região já contava com uma vida cultural muito antes do ciclo gomífero começar a modernizar a Amazônia. É muito provável que tenha recebido, em seu passado setecentista, um fluxo maior de óperas e gêneros assemelhados, se consideradas as notícias escassas que despontam aqui e ali. Segundo o Bispo João Queiroz (1760-63), sabese que entre 1761 e 1762 funcionava um teatro em Belém, de cujas comédias ali encenadas destacava de modo crítico a autoria das óperas com texto de Antonio José da Silva (1705-1739), o Judeu (QUEIROZ, 1961, p. 405). Traduções do célebre libretista Metastasio foram levadas à cena em Vila Nova de Mazagão no ano de 1777 , por ocasião da 
aclamação de D. Maria I (PALMA MUNIZ, 1916, p. 424), sem que se saiba a autoria da eventual música que se agregou a estes textos ${ }^{2}$. Décadas mais tarde, pelo nascimento de Maria Thereza, Princesa da Beira, foram representados no Teatro do Pará - obra do arquiteto Antonio Landi (17131791), mandada construir por João Pereira Caldas (1724-1794) - outros títulos em moldes semelhantes aos vistos em Mazagão; tratavam-se das óperas Ezio em Roma e Zenobia³, da comédia $A$ beata fingida, do drama pastoril Pastores do Amazonas, de Bento Aranha (1769-1811) e de um drama recitado de autoria de José Eugênio de Aragão e Lima (1794, p. 03).

Pouco mais se sabe de representações no atual território da Amazônia, durante o Antigo Regime. Com as diversas revoltas regionais no período pós-Independência e a vida da Corte em suspenso durante a Regência, foi necessário esperar até meados do século XIX para as principais capitais brasileiras reiniciarem o contato com a ópera. A retomada de funções operísticas no Rio de Janeiro, a partir de 1844, acompanhada da chegada de companhias artísticas também para Recife e Salvador em 1845, aqueceu a atividade lírica no país. Logo em 1855, a cidade de São Luiz, no vizinho estado do Maranhão, recebeu sua primeira temporada, mas no Pará isto ainda demoraria por acontecer. Efetivamente, até 1880, de natureza operística, Belém só assistiu a recitais líricos de artistas que haviam circulado por Pernambuco, Bahia e Rio de Janeiro.

Dentre as principais motivações para o incentivo que a governança de algumas províncias e a Corte concedeu à Ópera estão: o fomento à sociabilidade dos altos estratos, logo abrangendo estratos médios, em vista da subvenção dos espetáculos; o aspecto educativo do gênero, quer pelo seu texto ou música; a formação de novos hábitos, sobretudo, ao estender a vida em público para o horário noturno; a dinâmica comercial associada ao espetáculo e à vida noturna; e a dimensão artística profissional com a entrada de novas e variadas tendências estéticas em expressões artísticas diferentes.

O jovem imperador esteve sempre desejoso de dialogar com as primeiras nações do mundo ocidental em condições de igualdade e intentou uma política cultural que pode ser relacionada com o que se passou nas províncias prósperas do país. Assim, como Pedro II deu atenção a criação de uma Ópera Nacional, começaram a abrir suas portas muitos teatros provinciais e neles seguiuse um fluxo constante de companhias dramáticas e musicais. Como disse o eminente botânico Barbosa Rodrigues que viveu em Manaus no século XIX:
A força moral de uma nação não se determina só pelo número de seus soldados ou de seus vasos de guerra, pelo incremento de seu comércio e de sua indústria, mas principalmente pelo gráo a que teem atingido as sciencias, as lettras e as artes (RODRIGUES, 1892, p. V).

Foi, portanto, neste ímpeto que surgiu o Teatro da Paz, de Belém do Pará. Também porque, nesse caso, já não era possível pensar em uma demanda pública por espetáculos teatrais de diversos gêneros para serem colocados em pequenos espaços, sem as condições necessárias que exigiam as companhias itinerantes. Sua inauguração, em fevereiro de 1878, foi seguida de uma larga temporada de teatro declamado pela Companhia Dramática de Vicente Pontes de Oliveira (1834/5-1882). O mesmo empresário ocuparia ainda a pauta do Teatro da Paz no primeiro semestre do seguinte ano de 1879 , com a mesma companhia, gozando de um contrato de cinco anos, acordo que ficaria abalado pela dispensa do elenco e a falta de perspectiva de se reorganizar a tempo. Foi nessa oportunidade que se formou uma Associação Lírica Paraense, para buscar, junto ao empresário Tomas Passini, uma companhia lírica.

Assim, a primeira temporada lírica do Teatro da Paz começou em 7 de agosto de 1880, com Ernani, de Verdi, "espetáculo em festejo para inaugurar a ópera italiana nesta capital" (O Liberal do Pará, 7 ago. 1880). Desta data até 22 de outubro do ano de 1880, o público do Teatro da Paz assistiu aproximadamente quatro dezenas de espetáculos, entre récitas de assinaturas e extraordinárias, com um cartelão de nove óperas, sendo quatro delas de Verdi, Ernani, I/ trovatore, Un ballo in maschera e Rigoletto, e as demais de Donizetti, La favorita e Lucrezia Borgia, de Bellini, representado pela Norma, de Marchetti, com seu Ruy Blas e Carlos Gomes, com // Guarany.

A esta temporada inaugural Ihe seguiram outras quatro estações anuais de grupos operísticos, 
período em que se destaca a estreia de Idália (1881), do paraense Henrique Eulálio Gurjão (1834-1885), além da vinda de cantores de maior nomeada e de um enriquecimento do repertório com mais estreias.

O Teatro da Paz passou por uma reforma de poucos anos, em fins desta mesma década, ante de voltarem as temporadas líricas ao seu palco. Quando isto aconteceu, já se vivia a etapa republicana e, a partir de 1890 , se desenvolveu uma boa sequência de espetáculos líricos, embora nem sempre anual, que durou até 1907. Nesta altura, os palcos de Manaus, inicialmente o ÉdenTheatro e depois o Teatro Amazonas, passaram a acompanhar o movimento lírico do Teatro da Paz, compartilhando companhias, artistas e repertório.

Considerado o conjunto das temporadas destes quase trinta anos em Belém, pode-se perceber que as companhias traziam quase sempre repertório consolidado e pequeno número de cantores famosos e experientes, para atrair os subsídios públicos diretamente do governo provincial ou estatal, e também das respectivas associações líricas do Amazonas e do Pará. Mas estes nomes não conseguiriam envergar meses de apresentações consecutivas, com repertório de 10 a 20 títulos, sem se revezar com cantores mais jovens, que tivessem voz e talento para segurar a alta demanda.

Assim, a região assistiu a intérpretes excepcionais, tanto na condição de nomes afamados, como Adele Bianchi Montaldo, Carlo Bulterini, Giulio Ugolini, Franco Cardinali e Tina Poli Randaccio, como aqueles que já estavam construindo sua fama no percurso, como Libia Drog, Francesco Bonini, Gino Martinez Patti, ou o maestro Giorgio Polacco, dentre outros nomes reconhecidos da lírica internacional daqueles dias. Sem embargo, também era importante que estas companhias tivessem jovens cantores, saídos dos teatros italianos e europeus de porte médio ou superior, de onde se destacavam por seus dotes musicais e dramáticos. Muitos deles tiveram passagens rápidas e fulgurantes, alguns alcançando o topo da carreira muito rapidamente para desaparecer repentinamente como Alessandro Arcangeli e Antio Ceppi, outros que tiveram uma enorme aceitação popular, sem jamais ter se encaixado nos palcos famosos, como Amalia Agostoni. Mas, a grande maioria tinha muita prática e antes de chegar à Amazônia já tinha um percurso pontuado por muitas apresentações e em boas casas.

Estas temporadas das capitais do norte brasileiro tinham como uma dúzia ou uma vintena de títulos apresentados em cinco, seis, sete dezenas de recitais em um espaço de tempo que podia ser como de dois a cinco meses. Por vezes, uma temporada tinha vinte títulos em menos de dois meses, sem repetições, como decorreu em 1905, o que já é uma façanha.

Cada temporada tinha um acertado equilíbrio estético. No século XIX, seguiu sendo assim: uma parte majoritária, algo perto de metade, das óperas assistidas era de Verdi e a outra parte reunia óperas dos compositores de primo ottocento, especialmente Donizetti, mas também Bellini e Rossini (De Bellini somente Norma e Sonnambula, assim como de Rossini somente // barbiere di Sivig/i) somando-se a estes alguns poucos contemporâneos de Verdi que foram trazidos a estes espectadores do norte brasileiro, como Marchetti, Petrella e Ponchielli. Mas nem todas as óperas de Verdi entram nessa conta, mesmo que o autor contasse com predileção. Se considerado o período de 1880-1907, apenas 7 das 21 obras do autor eram levadas de modo recorrente nessas digressões: /l trovatore, Ernani, La traviata, Rigoletto, La forza del destino, Macbeth e Otello. Também para o caso de Donizetti, Bellini e Rossini, as companhias se ocuparam de selecionar os títulos que mais certamente renderiam nas bilheterias. Para o caso do primeiro estavam Lucia di Lammermoor, La Favorita, Lucrezia Borgia, Linda di Chamounix, Poliuto e Maria di Rohan e Don Pasquale, sendo várias delas apresentadas em somente uma temporada. Mas Bellini e Rossini foram muito menos divulgados entre os nortistas, sendo encenadas exclusivamente do primeiro a Norma, e ainda por uma temporada La sonnambula, enquanto do segundo somente il Barbiere di Siviglia sobreviveu.

Posteriormente, a partir de 1900, Puccini passou a ocupar um espaço preferencial no gosto do público de Manaus e Belem, sneod La bohèmea sua primera ópera nos palcos do norte, estreando-se em Belém em 1900 e Manaus em 1901. Com ele, alguns dos produtos de Mascagni, Leoncavallo e Giordano apareceram e assim aposentaram alguns 
títulos ods autores precedentes. Mas destes três autores naturalistas, não se viu nada além de seus capolavori, respectivamente Cavalleria rusticana, Pagliacci e Fedora; para o caso de Mascagni é notável que Iris tenha sido encenada, em vista da sua temática.

Também foram introduzidas as óperas de autores franceses, ainda que em sua corrente tradução italiana, como era costume nos palcos por onde passavam as companhias geralmente vindas da península. Assim foram assistidas duas óperas de Meyerbeer: Les Huguenots como Gli Ugonotti, versão com cortes habituais na partitura, e L'africaine como L'africana.

As últimas temporadas (1906 e 1907) foram de óperas em língua francesa, originais de autores italianos ou não, exceto La bohème e // Guarany que eram traduções. A preferência do trabalho de Puccini é muito explicável, em virtude de haver outras traduções sendo tentadas à época. Mas a presença da bem sucedida ópera de Carlos Gomes está relacionada com outros elementos de suas próprias belezas e isso fez com que o empresário Joaquim Franco, responsável por estas temporadas francesas, e o regente de sua companhia, Edouard Boni, recorressem ao poeta, regente e professor de canto Jules Algier (c.1873-1933) para uma tradução exclusiva que foi estreada em Manaus e Belém (1907).

Na composição das temporadas do Teatro da Paz foi igualmente frequente que estivesse uma ópera de autor brasileiro incluída. Gomes e /l Guarany foram a primeira opção, repetindo-se em várias ocasiões e Belém a assistiu em 1880, 1883, 1892, 1894, 1896, 1900, 1901, 1905 e 1907. Salvator Rosa foi assistida somente uma vez, em 1882, não havendo nenhuma outra de Gomes que se tenha apresentado naquela altura. Mas os autores amazônicos, ou integrados à região, também foram incluídos na conta. Nesse caso, ou porque os contratos com os empresários teatrais exigiam uma ópera nacional, ou porque o compositor era ao mesmo tempo o empresário da companhia.

Além de Gurjão, que teve a oportunidade em 1881, o violoncelista e compositor Ettore Bosio (1862-1936), que viveu muitas décadas na região, pôde estrear O Duque de Vizeu em 1892, repetindo-a em 1893, e mais tarde Ideale, em 1900. Entretanto, o único dos compositores paraenses que atuou como empresário para estrear seu trabalho foi José Cândido da Gama Malcher (1853-1921).

Filho de um médico que havia governado a província, interinamente, em três ocasiões, desde finais da década de 1870 até princípios da década seguinte, Malcher cumpriu desejo paterno cursando engenharia na Universidade de LeHigh, da Pensilvânia, Estados Unidos, de onde saiu em 1877 para estudar música em Milão. Estava de regresso a Belém em fins de 1881, havendo obtido a subvenção para a temporada lírica de 1882 no Teatro da Paz, favorecido por uma coincidência de fatores. Este sucesso não se deu somente por suas condições políticas e artísticas. Além de tudo, havia prometido estrear uma ópera de Carlos Gomes sob a direção do próprio autor, o que de fato aconteceu, quando Gomes veio para a estreia do Salvator Rosa.

A presença de Gomes em Belém no ano de 1882 foi de tal modo bem sucedida, que o compositor se tornou impresario e montou uma companhia itinerante no intuito de divulgar suas óperas. Esta começou a se exibir em 1883 no Teatro da Paz, onde também fracassou por causa de dívidas e desacertos internos.

Neste meio tempo, Gama Malcher partiu novamente para Milão, com a idéia de concluir sua primeira ópera, intitulada Bug Jargal. Oscar Guanabarino afirma que foi terminada de escrever em 1885 (O Paiz, 27 fev 1885). Ela demoraria cinco anos para estrear. Antes disso, em 1888, uma ária e uma romanza foram cantadas em concerto no Hotel Milan, em Milão, em s1888, perante a família real do Brasil; na ocasião, foi estreada no Teatro Dal Verme a ópera Carmosina, de João Gomes de Araújo, que havia sido bolsista de Pedro II na Itália.

A estreia de Bug Jargal aconteceu em 1890 no Teatro da Paz, quando Malcher surgiu como empresário da companhia subvencionado pelo governo do estado. A ópera seguiu para São Paulo, onde foi vista no Teatro São José, depois para o Rio de Janeiro, sendo levada no Teatro Fênix e no Teatro Lírico, tendo a empresa do compositor paraense falido ao fim da digressão carioca.

Malcher tornou a escrever uma ópera nos anos seguintes. Jara teve liberto publicado em 1894 e 
estreou no Teatro da Paz somente em 1895, durante temporada subvencionada pelo governo do Pará e a Associação Lírica Paraense. Com seu fracasso empresarial, esta companhia não seguiu viagem para outro teatro e a segunda ópera de Malcher não alcançou nem sequer os caminhos da primeira.

A música de ambas sobreviveu. Na Biblioteca Alberto Nepomuceno, da Escola de Música da Universidade Federal do Rio de Janeiro encontram-se as versões orquestra, para canto e piano e partes cavas de Bug Jargal. Malcher dedicou a sua partitura orquestral da Jara ao conservatório musical do Pará4.

As duas óperas têm fortes compromissos com a inquietude estética da lírica de seu tempo. Enquanto as temporadas e o repertório que nelas se integrou visava a regularidade e a formação do gosto das plateias do norte brasileiro, as óperas de Malcher adotam valores que mostram que sua criação lírica intentava buscar padrões de linguagem próprios, a partir de modelos reconhecíveis.

Em Bug Jarga/Malcher construiu muitos dualismos, talvez influenciado em sua juventude pelo célebre poema de Arrigo Boito, que foi o iniciador de uma nova corrente estética que alcançou Malcher. 0 Dualismo causou influências nas gerações de novos compositores a partir da década de 1870 , chamados scapigliati e nesse caso Malcher se enquadra bem na corrente estética, o que inclui além do jogo dualista, maior participação da orquestra e da música sinfônica, com passagens descritivas e as articulações entre o real e o metafisico, dentre outros aspectos (KIMBELL, 1991, p. 571). O tema de Bug Jargal se inspira no primeiro romance de Victor Hugo, sobre o episódio histórico da independência do Haiti, sob um severo conflito de brancos e negros. O tema foi propositalmente escolhido por ser contundente na discussão do abolicionismo a ser implementado num Brasil escravagista e preconceituoso. Malcher dá ênfase ao caráter heroico do protagonista, mas, sobretudo, aos valores universais que deveriam medir os seres humanos ao invés da raça ou condição econômica, como o amor fraternal, a lealdade, o sentido de comunidade, o desejo de emancipação e a superação das convenções em busca de um bem maior.

Malcher foi buscar o seu libretto em Vincenzo Valle (1857-1890), também do círculo scapigliatti,

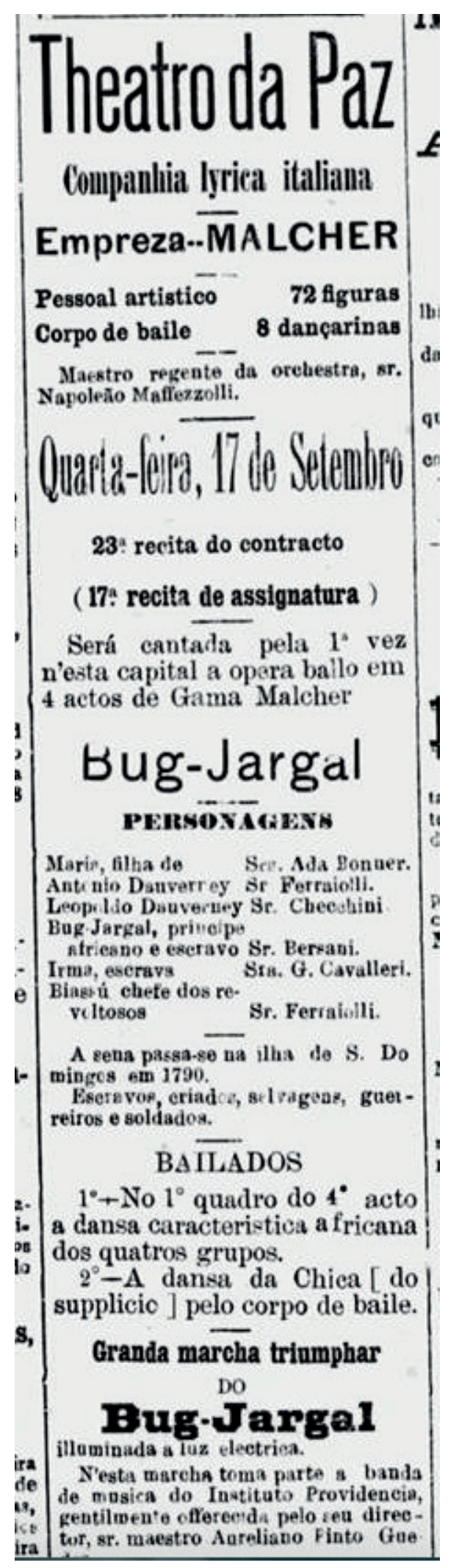

Figura 1 - Anúncio de estreia de Bug Jargal, onde se lê a distribuição do elenco, as partes onde constarão bailado, o uso de luz elétrica na grande marcha triunfal do Ato IV, além da ênfase que Malcher sempre dava ao fato da companhia ter 72 participantes e contar com corpo de baile de 8 pessoas. Fonte: Diário de Notícias, 17 set.1890. 
que era também tradutor e cujo trabalho mais famoso foi Labilia, que obteve com a música de Niccola Spinelli (1865-1909) o segundo prêmio do célebre concurso da Casa Sonzogno, em que a vitoriosa Cavalleria rusticana começou fulgurante carreira. Malcher e Valle adotaram a forma do melodrama em quatro atos, que marcou a obra de Verdi e seus seguidores.

Em Bug Jargal a estrutura dos dois atos externos é semelhante e configurada ao contrário dos dois atos internos: o ato I começa com coro e encerra com solos, neste caso um dueto, assim como o ato IV. Atos II e III começam com solos e terminam com coros. Isto garante que os atos I e IV partam das tensões coletivas para tentar resoluções individuais, enquanto os atos II e III fazem o caminho oposto, saindo de um conflito individual crescendo para o âmbito coletivo. Sem dúvida os atos internos são o ápice de toda a tensão e o mais curioso é que a ópera não se encerra com um coro, uma ação heróica ou mesmo uma participação do personagem principal. Na verdade, quando chega a última cena Bug Jargal já morreu e seus feitos e exemplos são recordações dos sobreviventes. Há aqui uma visão naturalista muito particular, de que a vida não se acaba em grande, mas permanece na memória daqueles que nos recordam. O dualismo, seja ou não de tensão/resolução foi explorado de muitas maneiras em Bug Jargal.

Há as diferenças da sociedade branca, baseada em uma ordem familiar, pois os personagens brancos são todos de uma mesma família, e da sociedade negra mais heterogênea, unida por uma causa ideológica coletiva, que é a liberdade dos negros; fica evidente o choque entre os representantes do capitalismo patrimonialista hereditário e o coletivo dos despossuídos que buscam na força social a sua emancipação.

Há ainda exemplos duais maniqueístas, no conflito entre os bons e os maus, e entre os puros e impuros, que são as vozes agudas (heroicas) contra as vozes graves (sombrias), ou inclusive na divisão numérica de personagens, três de cada parte. Os brancos Maria (soprano), Leopoldo (barítono) e Antonio (baixo) são da família D'Auvergney. Antonio, colono tirânico, é pai de Maria, que é prometida de seu primo Leopoldo, um tenente das tropas francesas na possessão de Santo Domingo. Bug Jargal (tenor) é um líder negro desde seus tempos de África, mas cai apaixonado por Maria depois de uma atitude de bondade dela para com ele. Irma (mezzo-soprano) é uma escrava enamorada de Bug Jargal e Biassu (baixo) é o vingativo líder negro.

Malcher e Valle criaram uma personagem que não se encontra em Hugo. É a escrava Irma, um papel de mezzo que está escrito contralto na parte, e que às vezes tem saltos e agilidade mais comuns à tessitura de soprano. Talvez esta seja uma das partes transicionais da literatura operística em que se vê o nascimento da soprano dramática naturalista. Há mais neste sentido para explicar.

A parte poético-musical de Irma tem frases inacabadas, soltas, a farfalhar, e mesmo com gritos; tem cantabiles originais, construídos sobre danças da região do Pará (lundú e carimbó), onde transparecem os ritmos característicos e detalhes harmônicos fora da tradição tonal, insinuando o uso de pentatônicas. Taos recursos eram absolutamente novos, não apreciados antes nas referências da geração anterior de Malcher (Gomes, etc.), fazendo de Irma um personagem telúrico, fruto de um desejo do autor por um naturalismo nacionalista.

Esta elaboração com profundidade estéticofilosófica tem sua razão de ser. Malcher foi um admirador confesso de Richard Wagner. Há um artigo que escreveu para publicação depois destas óperas, em que afirma ser Wagner "O maior vulto da música do nosso tempo" (SALLES, 2005, p. 243). Mais que declarar isto, ele escreveu um leitmotiv para cada um dos personagens de Bug Jargal, em certos casos até mais de um tema condutor. O conceito não deve aqui ser confundido com os temas recorrentes em uso na ópera italiana de seus antecessores mais conhecidos. Trata-se de um artifício de identidade emotiva, que logra atribuir à orquestra um papel semelhante de construção de caráter. A orquestra em Bug Jargal descreve uma guerra, as paixões, os rituais de sacrifício.

A orquestra também é fundamental em Jara pois toda a descrição da natureza é ela quem a representa, porque é a natureza a dimensão emotiva de Jara. Este tema pode ser uma intenção naturalista, mas tem contornos simbolistas muito fortes. A lenda da lara é muito conhecida hoje, mas tinha dispersão muito restrita na segunda metade do século XIX. Malcher tomou como 
base uma publicação italiana pioneira, fruto do trabalho do geógrafo Ermanno Stradelli (1885). Este italiano, que herdara o título de conde, havia nascido em Borgotaro e se laureado e Direito, mas viveu pelos rios da Amazônia por décadas e compilou lendas indígenas, dando-lhes formato narrativo. Eiara foi então o título da narrativa e poema que Stradelli publicou, segundo ele uma variação de Oiara ou I-Yara, também usados. As dificuldades com a linguagem fonética e os sinais disponíveis preocuparam Stradelli a ponto de escrever um inédito dicionário de nheengatu (1929). A sua publicação feita em Vicenza está em italiano, porque seguramente ele queria divulgar seu conteúdo para o ambiente europeu. Mas ele recheia de palavras em nheengatu, não exatamente para dar cor local, mas introduzindo elementos culturais que deseja que sejam compreendidos a partir do idioma. Stradelli mostra a forte interação da Natureza com a concepção mítica da lara.

Stradelli conta que o tapuio Begiuchira se encantou de uma visão na selva: uma sedutora mulher desconhecida e seu canto inesquecível. Desde este dia não a esqueceu mais. Com seu coração sobressaltado, uma tristeza profunda e a ideia fixa naquela aparição, se tornou facilmente prisioneiro dos encantos da lara, que o arrasta para as profundezas das águas escuras dos rios. Stradelli disse ter ouvido a lenda da lara por todos os lugares da Amazônia onde esteve e também que era ela uma encarnação feminina de Boiassú ou Boiuna, serpente gigantesca destas terras, que por ver avançar os homens nos domínios da natureza, se transforma em uma bela mulher para destrui-los espiritual e fisicamente.

Malcher percebeu as associações e se valeu delas para sua ópera. Escrita em italiano, Jara também adota em certos trechos o idioma nheengatu. Isto poderia ser interpretado como um elemento naturalista e possivelmente ninguém falava o nheengatu nas plateias que assistiram a ópera. O nheengatu teria assim uma função protosimbólica de diferenciar as linguagens e os povos, assim como suas condições existenciais. Esta dualidade não é um mero acaso. Como Stradelli já dissera, havia semelhanças com as ninfas, loreleis, ondinas e seres similares. Havia também elementos telúricos, muito regionais. Mas, sobretudo, se deve reconhecer que é uma história fantástica, com densidade psicológica e emotiva, de grande dimensão simbólica, pois encarna etapas da anima no imaginário primitivo.

Para converter em ópera, houve um tratamento de libreto por parte de Fulvio Folgoni. Malcher afinal pouco se baseou nisso. Aproveitou trechos diretos da obra de Stradelli para retratar a pequenez e o isolamento do homem frente a grandiosidade da natureza que na Amazônia tem dimensões subjugadora, que o italiano muito atentamente descreve. A ópera tem somente quatro personagens. Jara e os índios Begiucchira, Sacchena e Ubira; este último, como Irma em Bug Jargal, é uma criação do compositor com vistas ao equilíbrio dramatúrgico e ao desenvolvimento estético. É Ubira quem fala em nheengatu e sua presença e tessitura vocal de barítono lhe dá um reforço dramático, o temor que todos têm das forças descomunais da natureza que estão representadas em Jara.

Parte desta ideia de força não é propriamente do personagem principal, ainda que Jara seja um papel de soprano dramático. É o poder da música orquestral com aspectos descritivos muito ricos e de mais responsabilidade na compreensão da peça que em Bug Jargal. Malcher escreveu música sinfônica para uma alvorada amazônica e outros momentos interludiais. A escrita da parte de Begiuchira, como foi a de Bug Jargal, se destina a um tenor lírico spinto. Mas enquanto Bug Jargal é um herói que sucumbe para dar o amor como resposta a um mundo conflitivo, Begiuchira sucumbe porque é a perda da pureza humana frente ao descobrimento de um amor destrutivo. Enquanto Bug Jargal vai descobrir o amor fraternal pelas atitudes de sua heroína, Maria, o índio Begiuchira que somente amava filialmente sua mãe Sachena, se vê, ao conhecer Jara, tomado pela chama corrosiva da paixão que o turva, como eram os pressupostos do mundo em Bug Jargal. A música de Begiuchira é como una balada constante, de igualdade de formulação rítmica, pois sua vida se desenrolava assim até conhecer Jara. Mas nada se compara à elaboração musical que Malcher fez para a orquestra, evidenciando que o verdadeiro protagonista não foi antropomorfizado e domina a dramaturgia do início ao fim.

A estrutura de Jara é de prólogo e dois atos (segundo libreto e anotações da partitura também 
foi assumida em algum momento como sendo em três atos) e sua extensão é pequena para os padrões de outrora, talvez influenciada pelas produções exitosas recentes de Mascagni e Leoncavallo. O prólogo de Jara por exemplo não tem mais do que uma rica introdução orquestral, o cantabile de Begiuchira e uma parte de coro.

Nas duas óperas as árias são raras e seu conceito é diferente dos antigos modelos. Isto porque o recitativo melodramático é a estrutura predominante, com cantabili inseridos sem divisões formais. Entretanto, enquanto Bug Jargal tem mudanças e agógicas em alta profusão, Jara é muito mais linear, ainda que isto não signifique monotonia de condições dinâmicas. Especialmente em Bug Jargal o planeamento tonal nunca é seguido por seu autor e troca constantemente. Jara é algo mais monolítica neste sentido, pois as intervenções fora da regra precisam causar impacto.

Bug Jargal chamou a atenção da imprensa da época, incluindo a da Itália ${ }^{5}$ por reunir elementos que recordavam outras óperas e autores, mas o crítico carioca Oscar Guanabarino, que escrevia em O Paiz, do Rio de Janeiro, admitiu que na verdade era muito dificil dizer a que escola estava filiado o autor (Op. cit.). A Jara por seu turno agradou a plateia do Teatro da Paz pelos coros, cenários e montagem:

O $3^{\circ}$ ato resume com admirável engenho as melhores jóias musicais de toda a ópera, e prepara o espírito do espectador para um maravilhoso desenlace, que se realiza na surpreendente mutação para o quadro final. A mis-en-scene deste quadro é deveras original, representando o fantástico leito do Amazonas, com toda a riqueza do mundo dos mares. É aí que terá então lugar um esplêndido bailado, por um corpo de baile composto de Ninfas, Nereidas, Naiades, Oceânides, terminando por uma soberba apoteose à protagonista Yara, no seu fantástico reino, ornado de conchas, algas, pérolas, corais, etc. Aos múltiplos recursos de que dispõe a arte cenográfica, está reservada uma boa parte do efeito teatral da ópera, especialmente no cenário do quadro final, onde o pincel reprodutor das belezas naturais tem uma palheta enriquecida de caprichosas tintas, nos variados matizes dessa eterna primavera que margina as caudalosas águas do Rio-mar (A Época, 16 jul. 1895).

Mas quando a orquestra ficou tocando por longos minutos em cena aberta, mesmo que diante de uma representação do alvorecer amazônico, o efeito não parece ter sido o mesmo:
A má lembrança que teve o Maestro Malcher de fazer executar depois do intermezzo o prelúdio, gastando nisso perto de meia hora, em cena aberta e vazia, causou péssima impressão no público, que guardou completa frieza até o terminar do espetáculo (O Democrata, 8 maio 1895).

Malcher, sem as preocupações de outros compositores europeus, escreveu suas óperas à luz do ecletismo cultural que é muito visível e característico da arquitetura das capitais amazônicas. É afinal um modo particular de ver o caminho entre a tradição romântica e o modernismo, uma transição que adotava a scapigliatura e o wagnerismo, mas que estava em busca de respostas de cor nacional, regional e individual, apontando ao simbolismo, sem deslocar nenhuma das muitas vertentes da cultura desta parte do Brasil.

\section{NOTAS}

1. Uma efetiva política no ensino público do Amazonas foi iniciada em 1870. As crianças em idade de aprender as primeiras letras, que mais se destacavam em cada escola, obtinham subvenções para lograr estudos até a etapa liceal. Nesta fase, o aluno podia obter também subvenções para a conclusão do curso e escolher onde desejasse fazer sua graduação superior, dentre faculdades do Brasil ou de outros países. A província lhes custeava tudo. Depois de graduar pessoas em Direito e Medicina, dentre outros cursos, o Amazonas criou sua própria universidade em 1909.

2. Os títulos eram: Enéas em Getúlia, Dido desesperada, destruição de Cartago, o mais heroico segredo ou Artaxerexes e Demofonte em Trácia, que são prováveis versões de Eneal nel Lazio, Didione abbandonata, Artaserse e Demofoonte. As versões traduzidas, quando levadas à cena, incorporavam música de vários autores, originalmente compostas para obras de outrem, até mesmo sobre textos diferentes.

3. Ezio em Roma é tradução direta de Ezio, de Metastasio, acrescentando-se personagens cômicos, assim como Zenobia, também do autor italiano e submetida ao mesmo processo de conversão ao gosto português do período.

4. Bug Jargal tem cotas 3269 y 3270 no citado arquivo, mas Jara não tem registro arquivístico. 
5. A encenação no Pará foi criticada pela Gazzeta Musicale di Milano, publicada em 3 de novembro de 1890, por $a-x)$.

\section{REFERÊNCIAS}

RODRIGUES, João Barbosa. Vellosia. Contribuições do Museu Botânico do Amazonas. $2^{\mathrm{a} e d:}$ Rio de Janeiro: Imprensa Nacional, 1892.

KIMBELL, David. Italian opera. Cambridge: Cambridge University Press, 1991.

LIMA, José Eugénio de Aragão e. Drama recitado no Theatro do Pará ao princípio das Operas, e Comedia nelle postas pelo Doutor Juiz Presidente da Camara, e Vereadores, do anno de 1793 em applauso do fausto nascimento de Sua Alteza Real a Serenissima Senhora D. Maria Thereza, Princeza da Beira, e presumptiva herdeira da Coroa de Portugal. Lisboa: Officina de Simão Thaddeo Ferreira, 1794.

MALCHER, José Cândido da Gama. Jara: leggenda amazônica, opera lirics in tre atti/ parola e musica de maestro Gama Malcher/rappresentata La prima volta nel teatro DA PAZ AL PARÁ (Brasile) 1895. Milano: Moreo Virginio, 1894.

PALMA MUNIZ. Annaes BAP. V. IX, s.n. 1916.

QUEIROZ, Frei João de São José. Visitas pastorais: memórias / 1761 e 1762-1763. Rio de Janeiro: Melso, 1961.

SALLES, Vicente. Maestro Gama Malcher, Belém: UFPA, 2005.

STRADELLI, Ermanno. Eiara: leggenda tupiguarani, Piacenza, Vincenzo Porta, 1885.

VALLE, Vicenzo. Bug-Jargal: melodramma in quattro atti / parole di Vincenzo Valle; musica del maestro J.C. Gama Malcher - Milano: Gattinoni, Alessandro, 1890.

\section{MANUSCRITOS MUSICAIS}

MALCHER, José Cândido da Gama. Bug Jargal. Mellodrama in quatro atti. Manuscrito depositado na Biblioteca Alberto Nepomuceno da Escola de Música da Universidade Federal do Rio de Janeiro.
MALCHER, José Cândido da Gama. Jara. Opera in prologo e due atti. Manuscrito pertencente ao Instituto Carlos Gomes, de Belém, Pará.

\section{PERIÓDICOS}

A Época, Belém. 16 de julho de 1895.

Diário de Notícias, Belém. 17 de setembro de 1890.

Gazzeta Musicale di Milano, Milão. 3 de novembro de 1890.

O Democrata, Belém. 8 de maio de 1895.

O Liberal do Pará, Belém. 7 de agosto de 1880.

O Paiz, Rio de Janeiro. 27 de fevereiro de 1891.

\section{SOBRE O AUTOR}

Márcio Páscoa é Doutor em Ciências Musicais Históricas pela Universidade de Coimbra, com Pós-Doutorado em Música pela UNICAMP, tendo igualmente Graduação em Música pela UNESP, onde também obteve o Mestrado em Artes. É autor de diversos livros, capítulos de livro e artigos em periódicos científicos indexados, no campo da história da música, teoria musical, iconografia musical, bem como história cultural, concentrando-se nos séculos XVIII e XIX, especialmente no Brasil, seu contexto e influências, com destaque para o Norte brasileiro. E-mail:mpascoa@uea.edu.br 